\title{
Plantando nos campos do inimigo: japoneses no Brasil na Segunda Guerra Mundial
}

TANIA QUINTANEIRO*

\begin{abstract}
Resumo: Durante a Segunda Guerra Mundial, os Estados Unidos valeram-se das Listas Negras para eliminar as redes comerciais e as empresas vinculadas aos países do Eixo que atuavam nas repúblicas americanas. Este artigo analisa a política de guerra econômica aplicada no Brasil, especificamente com relação às cooperativas dos imigrantes japoneses, e a estratégia do governo Vargas para lidar com as pressões exercidas pelas autoridades do Departamento de Estado norte-americano.
\end{abstract}

Abstract: During World War II, the United States used the Proclaimed List of Certain Blocked Nationals as an instrument to eliminate the commercial networks and the companies associated to Axis countries operating in the American Republics. This article analyses the policy of economic warfare applied in Brazil, specifically in relation to the cooperatives of Japanese immigrants and the strategy of the Vargas government to deal with the pressures exercised by the State Department.

Palavras-chave: Brasil. Imigrantes japoneses. Listas Negras.

Key words: Brazil. Japanese immigrants. Proclaimed Lists.

Ao longo da Segunda Guerra Mundial, o Estado norteamericano pressionou, com variável êxito, os governos da América Latina para que efetivassem medidas de controle sobre empresas e nacionais dos países do Eixo. ${ }^{1}$ Peça chave dessa guerra econômica foi a Proclaimed List of Certain Blocked Nationals (PL), conhecida popularmente como Lista Negra, cujos comitês executivos eram formados por representantes de diversos departamentos estatais norte-americanos e sediados nas embaixadas ou legações que fun-

* Professora do Departamento de Sociologia e Antropologia da UFMG. taniaq@ufmg.br

1 Uma bolsa da FAPEMIG possibilitou a pesquisa nos National Archives and Records Administration, em Maryland, em fontes primárias do Departamento de Estado, da embaixada e consulados no Brasil, e de enviados especiais.

Estudos Ibero-Americanos. PUCRS, v. XXXII, n. 2, p. 155-169, dezembro 2006 
cionavam nos países da região. O objetivo da PL era o bloqueio comercial e financeiro de empresas ou pessoas consideradas indesejadas, impedindo que, em âmbito hemisférico, fossem realizados quaisquer tipos de transações com elas. Para reforçar essas disposições, aqueles que insistissem em manter negócios com os interesses bloqueados podiam sofrer as mesmas conseqüências: congelamento de contas bancárias, interdição de importar ou representar produtos norte-americanos e, no limite, intervenção e liquidação dos estabelecimentos. Com a assinatura, no primeiro semestre de 1942, das cartas do Rio Janeiro e de Washington, os Estados Unidos sentiram-se ainda mais à vontade para exigir das repúblicas aliadas da OEA a aplicação dessa política em seus territórios. Desse modo, procurariam barrar os interesses dos países do Eixo, atingindo a rede de distribuição de seus produtos e evitando que matérias-primas alcançassem suas indústrias.

No Brasil, a presença conspícua dos imigrantes italianos não inspirou cuidados às autoridades norte-americanas, mais preocupadas com tudo o que dizia respeito às populações alemã e japonesa. Esta última concentrava-se, particularmente, no interior do estado de São Paulo, sendo menos densa no Paraná, Minas Gerais, Mato Grosso e na região amazônica. Sua organização em comunidades isoladas e coesas colocou problemas específicos à implementação das medidas de controle exigidas pela política de guerra. Encravadas em pontos importantes da cadeia produtiva, tanto na agricultura de subsistência quanto na exploração e comercialização de materiais que se tornaram essenciais para a economia bélica, essas colônias constituíam uma complexa rede na qual se enlaçavam interesses das próprias potências Aliadas.

Se bem que o chamado "perigo amarelo" tinha sido esgrimido por alguns países, desde muito antes, para restringir a entrada de trabalhadores asiáticos, foi a partir de Pearl Harbor que os imigrantes japoneses foram alvo de uma repressão sistemática e concertada em todo o continente. Os instrumentos utilizados para neutralizar seus interesses envolveram bloqueio comercial, intervenção em empresas, e extradição de indivíduos a campos de confinamento nos Estados Unidos. O objetivo deste trabalho é, precisamente, analisar o conflito gerado pela aplicação da PL e seu impacto sobre essas comunidades no Brasil, e o papel desempenhado pelo governo brasileiro, responsável pela vigilância dos nipônicos e pela interferência em suas cooperativas, nas negociações com os Estados Unidos. 


\section{Características da migração japonesa ao Brasil}

Em decorrência das restrições impostas à entrada dos japoneses nos Estados Unidos, parte do fluxo migratório orientou-se, nas primeiras décadas do século $\mathrm{XX}$, para as repúblicas latinoamericanas, e, com intensidade muito maior, para o Brasil. Os governos estaduais viram nesse traslado a oportunidade de diversificação de cultivos e de desenvolvimento econômico e subsidiaram por um tempo as viagens; cafeicultores paulistas, carentes de mãode-obra, fomentaram sua vinda por meio de contratos de trabalho. Companhias privadas japonesas dedicaram-se a atrair interessados, garantir a instalação das famílias de trabalhadores em núcleos rurais e vender terras aos que conseguiam comprá-las por meio de financiamento de suas próprias casas bancárias, com vínculos com a Mitsui e a Mitsubishi. Houve também migração espontânea, incentivada por parentes já instalados no Brasil e de noivas, em casamentos arranjados à distância. Todas as companhias privadas de migração acabaram absorvidas até 1920 pela Kaigai Kogyo Kabushiki Kaisha (KKKK), a qual, fundada pelo governo japonês em 1917, passou a atuar como empresa estatal junto às colônias. ${ }^{2}$

Essa primeira geração de japoneses, assentados com suas famílias em áreas pré-fixadas pelos interesses econômicos locais, manteve fortes laços identitários com seu país de origem, inclusive o culto ao imperador, e procurou conservar sua cultura e seu idioma, por meio de escolas de ensino fundamental em língua japonesa, cujo funcionamento o governo brasileiro proibiu, no decorrer da guerra, em função de sua política nacionalista e assimilacionista. Uma das instituições sociais mais significativas na estruturação dessas comunidades foi a nihonjin-kai, formada pelos chefes de família, que promovia "atividades culturais, casamentos, e apoiava e coordenava o desenvolvimento local". ${ }^{3}$ A pretensão de retornar à terra natal e a vida em agrupamentos rurais pacíficos, dedicados à dura atividade agrícola, ao mesmo tempo em que promoviam a disciplina e coesão social, dificultavam a integração com os nacionais, e alguns japoneses sequer aprenderam o português. Um migrante disse ter encontrado, numa delegacia no Paraná, um grupo de 42 de seus patrícios, muitos dos quais idosos, que permaneciam

2 SAKURAI, Célia. Imigração japonesa para o Brasil: um exemplo de imigração tutelada (1908-1941). In: FAUSTO, Bóris (org.). Fazer a América. São Paulo: Edusp, 2000, p. 224.

3 NINOMIYA, Masato. Japanese Brazilian historical overview. In: KIKUMURAYANO, Akemi (ed.). Encyclopedia of Japanese Descendants in the Americas. Altamira Press: 2002, p. 119. 
presos há quarenta dias por serem incapazes de se comunicar com as autoridades. 4

Um braço dessa migração dirigiu-se à região amazônica. A Companhia Nipônica de Plantação do Brasil delimitou terrenos a 200 km de Belém, em plena selva, estabelecendo a Colônia Acará, depois denominada Tomé-Açu. Em 1929, chegaram ao Pará os primeiros imigrantes do Japão. ${ }^{5}$ A instalação, em 1931, em um projeto agrícola patrocinado pelo governo amazonense, dos koutakusseis, jovens agrônomos japoneses, é um indício das expectativas de aplicação de novos métodos de cultivo e de diversificação de culturas com a finalidade de promover o desenvolvimento econômico regional. 6

Como resultado de acalorados debates, de inegável conteúdo racista, sobre a política de migração que o Brasil deveria adotar, a Constituinte de 1934 e a lei de migração de 1938 definiram uma diminuta quota para a entrada de japoneses: $2 \%$ dos estabelecidos nos últimos 50 anos. Em 1939 chegaram ao Brasil apenas 1.414 japoneses e, em 1940, 1.471, pouco mais de $6 \%$ do total dos que haviam ingressado em 1934.7 Em 1942 e 1943 não houve migração.

\section{Inserção dos japoneses na economia brasileira}

Iniciada em 1908, a migração para o estado de São Paulo estava dirigida à pujante produção cafeeira, ainda capaz de absorver abundante força de trabalho. Segundo Ninomiya, o cultivo do café em terras paulistas reunia, em 1912, 92,6\% dos imigrantes japoneses, percentual que baixou em 1922 a $52,2 \%$, enquanto o plantio de arroz passava, nesses mesmos anos, de $2,5 \%$ a $17,6 \%$, tendo diminuído a partir de então. Mas a tendência à transferência entre culturas agrícolas foi notável no caso do algodão que, de $1,2 \%$ em 1912, passou a empregar $12,1 \%$ da mão-de-obra, e continuou a crescer, espalhando os migrantes também pelo Paraná. Empresas japonesas, associadas à KKKK, interessaram-se, a partir de 1936, por produção, processamento, beneficiamento, importação, expor-

4 WAWZYNIAC, Sindinalva M. S. Histórias de estrangeiro. Passos e traços de imigrantes japoneses (1909-1970). Tese de doutorado em História. Universidade Federal do Paraná, 2004, p. 96.

5 YANAGUIDA, Toshio; ALISAL, María Dolores R. de. Japoneses en América. Madrid. Editorial Mapfre, 1942, p. 230.

6 http://madeinjapan.uol.com.br/2003/06/08/associacao-conta-a-historia-dosjaponeses-no-amazonas. Consultado em 7/6/2006.

SMITH 30-9-1942. Japanese Immigration and the Number and Distribution of the Japanese Population in the State of SP, Brazil. RG 59, Central Files. 
tação e financiamento do algodão que, com o declínio do café, já absorvia 39,2\% dos imigrantes em 1932. 8 Nesse ano, a KKKK, visando a formar técnicos e instrutores, fundou o Instituto de Prática Agrícola de São Paulo. ${ }^{9}$

O comércio entre Brasil e o império japonês mostrou, a partir de 1933, um aumento significativo, e três anos mais tarde a balança entre os dois países tornou-se favorável ao Brasil. Isso se deveu à importação do algodão cru brasileiro, já que o acesso do Japão a antigos fornecedores tinha sido cortado enquanto sua produção têxtil encontrava-se em crescimento. O Japão se anunciava como potência industrial e procurava mercados para seus produtos. Nos anos de 1937 e 1939, as compras do algodão brasileiro pelo Japão alcançaram mais de dois milhões de libras ouro, e o percentual do algodão cru no valor total das exportações foi de $96 \%$ em 1937 e de 91\% em 1939.10 A visita de uma missão econômica japonesa pretendia incentivar as relações comerciais com o Brasil. Vale lembrar que o segundo maior comprador do algodão brasileiro era, então, justamente a Alemanha.

Em 1940, dos 205.850 japoneses residentes no Brasil, 35.381 dedicavam-se à agricultura, seguidos em importância pelos que trabalhavam no comércio, que perfaziam somente 2.286. Declararam-se sem profissão 161.467 , ainda que a atividade econômica exercida pelos migrantes ocupasse em geral mão-de-obra familiar. ${ }^{11} \mathrm{O}$ estado de São Paulo abrigava 94\% desses imigrantes, 87,2\% dos quais exerciam atividades agrícolas. Do setor agrícola, alguns passaram ao comércio e à prestação de serviços, na condição de pequenos empresários. As chácaras de hortaliças e granjas avícolas também atraíram crescentemente os japoneses, que se instalaram nas regiões circundantes dos grandes centros urbanos paulistas, logo que conseguiam liberar-se dos contratos com os produtores de café ou juntar algumas economias e adquirir terras. Em 1942, $19,9 \%$ dos japoneses dedicavam-se aos hortifrutigranjeiros. Sua produtividade adquiriu prestígio nacional em função do emprego de técnicas agrícolas inovadoras. Os funcionários norteamericanos estimavam que seu número representava, no estado, cinco vezes o dos estrangeiros de fala alemã.

8 NINOMIYA, op. cit. p. 121.

9 SAKURAI, op. cit. p. 231.

10 CHILDS. 13-3-1941. Japanese-Brazilian Economic Relations. RG 84, Confidential Files, v. I EC.

11 YANAGUIDA \& ALISAL, op. cit. p. 227-8. 
Os agricultores começaram a organizar-se em cooperativas com a finalidade de adquirir adubos e outros insumos. Sua concentração geográfica e a manutenção de sua cultura em terra estranha foi um fator facilitador a aproximá-los nessa modalidade organizacional, de resto vinda de uma longa tradição no Império do Sol Nascente. Segundo a Sociedade Brasileira de Cultura Japonesa, entre os anos de 1916 e 1932, 188 novas cooperativas foram registradas. ${ }^{12}$ Os norte-americanos confessaram que elas foram um dos problemas mais complexos que a embaixada precisou enfrentar no relativo à política da PL. ${ }^{13}$ Seus enviados relatavam que as comunidades de japoneses em São Paulo tendiam a distanciar-se dos nativos, diferentemente dos italianos, que se deixavam absorver facilmente. Seu isolamento, diziam, devia-se a que não era simples, para eles, tornarem-se brasileiros, apesar de o desejarem. Assim, dedicavam toda a atenção a seu trabalho e não havia "evidências de agitação antiamericana ou pró-Eixo entre os japoneses". Talvez por isso, ou mais provavelmente devido às grandes diferenças culturais e à motivação de juntar as economias para o desejado regresso ao Japão, tampouco havia "contatos entre japoneses e círculos de alemães ou italianos".14 Eles eram ditos "diligentes, e agricultores sagazes, comprando sua terra de uma vez ou pagando um aluguel direto. Eles são aparentemente vigiados de perto por seu governo e as companhias colonizadoras que os enviaram. Os japoneses não atuam na vida política". ${ }^{15}$ Em meados de 1941, as casas importadoras no Brasil ainda eram liberadas pelo comitê da PL para fazer negócios com o Japão, desde que o cônsul se certificasse dos "sentimentos" do importador. Estando convencido de que "é próbrasileiro e pró-americano", o comitê não fazia objeções.16 Algumas autoridades estadunidenses e brasileiras continuaram não vendo motivo para preocupar-se com os japoneses no Brasil, mesmo quando começaram a variar as avaliações sobre o perigo que representavam, e até finais de 1941 ainda se atribuía pouca importância política aos orientais.

2 Apud WAWZYNIAC, op. cit. p. 139.

Procurement of Strategical Materials 1943. RG 84, Strictly Confidential Files.

14 HEACOCK. 8-9-1941. Japanese in SP. RG 84, v. XVIII.

15 Brazil Handbook 1940. RG 151.

16 DONNELLY. 5-6-1941. RG 84, v. XX. 


\section{Entesourando materiais estratégicos}

O status político dos japoneses residentes nas repúblicas americanas sofreu mudanças importantes após o ataque a Pearl Harbor (7-12-1941). ${ }^{17}$ Em nome da defesa interna e da segurança hemisférica, os nipônicos começaram a ser alvo de estrita vigilância por parte dos órgãos de inteligência norte-americanos, e o número de agentes deslocados para a região aumentou, para avaliar, in loco, suspeitas de que eles poderiam estar favorecendo estratégias do Império. Por outro lado, certos empreendimentos japoneses no Brasil já tinham adquirido tamanho suficiente para serem notados, merecendo, eventualmente, considerações de bloqueio. $\mathrm{O}$ insulamento das comunidades podia servir para que, sem serem advertidas, se organizassem contra os Aliados que vinham dando crédito a qualquer conjetura. O próprio cônsul de São Paulo ouvira de uma fonte "presumivelmente confiável" que, no estado, "a organização militar japonesa divide-se em 25 quartéis generais. Existem cerca de 6.000 oficiais de reserva japoneses designados para os quartéis, agora congregados na Fazenda Tietê para receber instruções". ${ }^{18}$ Eles estariam esperando ordens de Tóquio para prosseguir. Segundo informes, estavam intensamente engajados em exercícios militares, tinham armamento, granadas de mão, revólveres e mesmo armas antitanque enviadas do Japão. Os oficiais militares, encaminhados pelo Japão para as colônias a fim de dirigir atividades militares, tinham estabelecido "uma máquina de guerra suficientemente eficiente para inspirar respeito". A conspiração para atacar o Brasil desde dentro rendeu preocupação para a inteligência norte-americana e envolveu nas investigações a polícia brasileira, que garantiu ter tido acesso a parte do plano. No entanto, até finais de 1941, só tinham sido encontrados e presos quinze oficiais, aos quais os relatórios oficiais estadunidenses não dedicaram maior importância. Em julho de 1917, um rumor semelhante tinha ocorrido no México. Propagou-se que havia um projeto de invasão japonesa aos Estados Unidos e que soldados japoneses, disfarçados de imigrantes, vinham sendo introduzidos secretamente em território mexicano, onde treinavam militarmente todos os dias ao anoitecer. ${ }^{19}$ Boatos

17 Cf: BARNHART, Edward N. Citizenship and political tests in Latin American Republics in World War II. The Hispanic American Historical Review, v. 42, n. 3, August, 1962, p. 297-332.

18 CROSS. 11-12-1941. Japanese Activities in SP. RG 84, v. XX.

19 YANAGUIDA \& ALISAL, op. cit. p. 162. 
de um complô nipônico, da descoberta de depósitos de armas e de um avião desmontado também surgiram no Peru, onde a multidão destruiu casas e lojas de japoneses.20

Vale destacar que, desde o final da década de 1930, a América Latina vinha tornando-se uma fonte de matérias-primas para o Japão que ambicionava também ampliar mercados para suas indústrias. Em 1940, a correspondência entre o Departamento de Estado e as representações mostra que os Estados Unidos estavam em alerta para o esforço nipônico em pesquisar o comércio e as condições de intercâmbio com a América do Sul por meio de missões econômicas e grupos de negociantes, havendo planos para uma exposição flutuante de maquinário em vários países. Associações comerciais japonesas programavam a chegada do navio aos portos do Rio de Janeiro, Santos e Belém. ${ }^{21}$ Por isso, um informe sobre o envio, para a América do Sul, de grande número de funcionários japoneses, particularmente de oficiais militares, no início dos anos 1940, causara intranqüilidade em Washington. Uma das hipóteses para o fato era que eles haviam sido incumbidos de fazer "lances mais altos do que os Estados Unidos para materiais estratégicos".22 A essa altura, o governo norteamericano, através de suas agências, tinha intensificado o cômputo de todas as atividades relacionadas com esse comércio. De fato, desde 1939, pelo menos, já vigiavam a aquisição de minerais nas repúblicas americanas. O cristal de quartzo era motivo de grande preocupação, já que vinha sendo usado crescentemente para fins navais e militares. Os relatórios davam conta das importações de "britânicos, alemães, japoneses e outros agentes compradores estrangeiros", e os consultores aconselhavam seu governo que cuidasse de aumentar as reservas, já que as perspectivas de paz não pareciam próximas. ${ }^{23}$ Aquela seria uma guerra travada com mais tecnologia e armamento pesado cuja fabricação exigia matérias-primas relativamente abundantes nos países da América Latina. A produção de quartzo de boa qualidade no Brasil era tão grande que se chegava a dizer que o estoque era ilimitado. Mas antes, comentavam confidencialmente os obser-

20 GLAVE, Luís M. \& LAURO, Claudia R. Imigração estrangeira para o Peru (18501930). In: FAUSTO, Bóris (org.). Fazer a América. São Paulo: Edusp, 2000, p. 521.

21 GREW. 28-2-1941. (Tokyo) Reported Forthcoming Visit of Japanese Floating Exhibit.

RG 84, Confidential Files, v. I EC.

22 WELLES. 25-9-1941. Increase in Personnel of Japanese Missions in Certain of the OAR. RG 84, v. XVII.

23 WINSLOW. 24-6-1939. Quartz Crystal in Brazil. RG 59, Central Files. 
vadores norte-americanos, seria necessário que os "métodos casuais, desorganizados e primitivos de exploração" fossem substituídos por uma indústria moderna e eficiente, um objetivo a ser alcançado com a ajuda de sócios técnica e politicamente adequados.

Os Estados Unidos vinham planejando executar uma captação racional e contínua de matérias-primas para sua indústria, em particular para a produção bélica e de bens de subsistência para os soldados e o povo norte-americano. Em junho de 1941, o Army and Navy Munitions Board classificou os materiais necessários em dois tipos: os críticos e os estratégicos. Estes eram os "essenciais para a defesa nacional, cujo fornecimento durante a guerra está colocado, como um todo ou em parte substancial, em fontes fora dos limites continentais dos Estados Unidos, e para cuja conservação estrita e distribuição serão necessárias medidas de controle". Os "críticos" eram aqueles cuja consecução na guerra seria menos difícil, ou por serem menos essenciais ou porque eram disponíveis em quantidades mais adequadas de fontes domésticas, e para os quais o grau de controle de conservação e distribuição seria menor, ainda que necessário. Tal classificação dependia de necessidades altamente cambiantes na conjuntura da guerra, da balança de poder entre os Estados Unidos e as repúblicas latino-americanas, em geral grandes fornecedoras dos materiais estratégicos, e, conseqüentemente, dos acordos que eram estabelecidos entre seus governos. O FBI apontava o Brasil como o país provavelmente mais importante na América do Sul para o programa de guerra dos Estados Unidos, não havendo outro no mundo com tantos recursos naturais, minerais e florestais: "é rico em ouro e outros metais preciosos, diamantes, carvão, ferro e vários outros materiais estratégicos". ${ }^{24}$ Os diamantes industriais, cristais de quartzo e a borracha estavam entre tais produtos, e viriam a fazer parte do conjunto de acordos celebrados a partir de maio de 1941 entre Brasil e Estados Unidos, dando a estes o monopólio na sua compra e excluindo de seu acesso as potências do Eixo, sob protestos de suas embaixadas. ${ }^{25} \mathrm{~A}$ atividade do Império do Japão na compra, na América do Sul, de antimônio, quartzo e diamantes já era considerada excepcional e vinha sendo monitorada. Em São Paulo, os envios de quartzo para

24 FBI. 21-3-1942. United States Dependency on South America. RG 226. Office of Strategic Services. Microfilm.

25 Nos novos acordos seriam incluídos vários outros produtos, como bandagens de algodão e fibras. Entre 1941 e 1943 foram assinados dezessete acordos sobre exclusividade norte-americana na compra de materiais estratégicos brasileiros. 
o Japão eram feitos pela Bratac, ${ }^{26}$ associada à KKKK. O Japão tinha sido, entre 1935 e 1940, o segundo maior comprador do cristal de rocha brasileiro, sendo a Inglaterra o primeiro. ${ }^{27}$ A intensificação do programa japonês de compras de quartzo acabou por inspirar um projeto de estabelecer no Brasil uma organização com esse propósito, afinal barrada pelo embargo brasileiro em função de acordos com o governo Roosevelt. A procura por diamantes também era intensa. O preço médio do quilate dos diamantes brutos exportados pelo Brasil em 1939 tinha sido de US\$ 10.00, tendo aumentado a US\$ 15.00 no ano seguinte, mantido a tendência de ascensão em 1941, até chegar a US\$20.00, e a expectativa era de que subiria ainda mais em 1942. Enquanto isso, a produção estimada em quilates não sofrera mudança. 28

Em março de 1941, as atividades relacionadas aos materiais estratégicos sobrecarregaram de tal maneira a embaixada dos Estados Unidos no Brasil que ela solicitou ao Departamento de Estado a nomeação de um encarregado para coordenar compras e contratos de entrega, encorajar a produção de produtos essenciais e recomendar créditos. Pedia que se enviasse um agente altamente capacitado, com dedicação exclusiva a essa função, já que o caos que caracterizava tais ações, e a atuação dos inimigos vinha acarretando ascensão dos preços e dificultando as compras. O indicado devia ter autonomia para contratar "os serviços de especialistas em diferentes ramos" e ter condições de avaliar de modo geral o trabalho dos consultores. ${ }^{29}$ A tendência a dotar de profissionais qualificados os órgãos estatais instalados fora do território dos Estados Unidos caracterizou a ação norteamericana durante a Segunda Guerra, especialmente quando o fornecimento de materiais estratégicos estava envolvido. No caso do Brasil, havia que assegurar o máximo controle sobre as reservas minerais, e a produção de borracha, algodão e outros insumos. Isso tornava críticas as ações dos imigrantes japoneses no Brasil, dedicados que estavam a produzir alguns dos materiais essenciais para a guerra, como o algodão em São Paulo, e instalados, na Amazônia, próximos às vias de escoamento da borra-

26 Bratac eram as iniciais Burajiru Takushoku Kumiai (Sociedade Colonizadora do Brasil) http:/ /www.bratac.com.br/empresa.htm. Acessado em 7/6/2006.

27 BRASIL. Divisão Política e Diplomática. 1-4-1941. RG 84, Strictly Confidential Files.

28 BURDETT. 18-3-1941. Availability of Raw Materials. RG 84, Confidential Files, v. III EC.

29 BURDETT. 5-3-1941. Coordination of American Defense Purchases in Brazil. RG 84, v. XXVI. 
cha, essencial para a fabricação de pneus. Eles poderiam colaborar com o Japão na compra desses produtos, sabotar seu escoamento ou contrabandeá-los. Segundo a embaixada, aproximadamente $50 \%$ das máquinas descaroçadoras de algodão no Brasil pertenciam a companhias norte-americanas ou britânicas que dependiam do esforço desses colonos. Em meados de 1941, roupas de algodão fabricadas no Brasil eram usadas pelo exército norte-americano. ${ }^{30} \mathrm{~A}$ articulação de interesses japoneses e norteamericanos no Brasil tornava quase impossíveis os cortes bruscos previstos pela PL. Em outras palavras, não havia como promover automaticamente a aplicação das restrições do bloqueio. Por outro lado, como bem notara o embaixador, "a grande população japonesa no Brasil, a tendência dos japoneses de operar companhias com nomes brasileiros e a confusão de subsidiárias, afiliadas e diretorias interligadas nas maiores firmas japonesas criaram uma situação para a qual é requerida uma investigação exaustiva como pré-requisito para a criação de uma PL de firmas japonesas". ${ }^{31}$ Sutilezas étnicas e culturais ajudavam no imbróglio, dificultando as tentativas de controle.

Quando, por fim, a PL conseguiu promover as interdições às cooperativas de São Paulo, o cônsul afligiu-se com a possibilidade de que o governo norte-americano não se desse conta da gravidade da situação a que haviam sido levados os produtores de algodão, sem financiamento ou mercados externos. ${ }^{32}$ Ele temia pelo prestígio da política de seu país, embora suspeitasse que Vargas não tivesse, nem viesse a ter, no futuro próximo, controle administrativo comparável ao que se dava sobre os nipônicos residentes em território norte-americano, muitos dos quais já estavam presos em campos de confinamento. $33 \mathrm{O}$ sistema de cooperativas agrícolas era disseminado entre os japoneses, e os efeitos adversos da inclusão delas na PL eram previsíveis. Por isso, as autoridades brasileiras, especialmente o Ministério da Agricultura e o Departamento de Agricultura do Estado de São Paulo, expuseram suas preocupações ao comitê.

30 18-6-1941. RG 84, v. XX.

CAFFERY. 17-12-1941. RG 84, Confidential Files, v. II B EC.

32 CROSS. 18-12-1941. RG 84, Confidential Files, v. II B EC.

33 DONNELLY. 24-12-1941. Contracts between Companies and Japanese Cotton Farmers. RG 84, v. IIB EC. 
A polícia paulista também estava apreensiva com o perigo de que as tensões e o desespero pudessem levar os agricultores à revolta. Colocar todos os japoneses no que os estadunidenses denominavam "campos de concentração ou de internamento", que no Brasil seriam colônias penais, fora considerado fora de questão e, dado que os colonos se estabeleciam, principalmente, em zonas rurais ou suburbanas, a embaixada preferiu recomendar que fossem seletivamente removidos os que moravam em certas áreas litorâneas estratégicas, e apoiar a vigilância exercida pela polícia brasileira. ${ }^{34}$ Esta retirou os nacionais do Eixo que viviam na costa paulista e levou-os a um "um campo de concentração já existente no interior do estado", tendo sido afetadas por essa ação mais de 10.000 famílias de todas as nacionalidades inimigas. ${ }^{35}$ No litoral do Espírito Santo, a ordem de traslado atingiu cerca de 300 pessoas, sendo apenas 5 japoneses, mas, segundo o delegado de Vitória, a maioria podia ser considerada inofensiva, assim como os pequenos agricultores do interior do estado. ${ }^{36}$ No Rio Grande do Sul, um novo "campo de concentração" para mil prisioneiros estava sendo construído em Guaíba, dado que os meios de acomodação estavam já superlotados, mas dentre os 400 presos havia somente 15 japoneses. ${ }^{37}$ Os funcionários norte-americanos alegavam que havia perigo de interrupção do fluxo das matérias extraídas e trazidas do Brasil para as fábricas nos Estados Unidos, e dada a grande dependência norteamericana de tais insumos, o FBI aconselhava que se mantivesse estritamente "a segurança dos materiais em seu estado original... tanto no processo de extração quanto no trânsito em alto mar para os Estados Unidos". 38 A proximidade de colônias de japoneses a reservas militares, portos e fortes, em Santos, em São Paulo, ao longo de rodovias no Mato Grosso e da Ferrovia Central do Brasil no trecho Rio-São Paulo, aumentava o temor de sabotagem das indústrias e vias de transporte dos valiosos produtos. No vale do Amazonas, poderiam afetar o transporte de borracha a caminho das forças aliadas, quando se esperava o aumento no suprimento de borracha amazônica graças aos esforços da Rubber Development Company para incentivar a produção.

\footnotetext{
COVILLE. 5-9-1942. Report on Japanese Problem in Brazil. RG 84, v. XXXII. 9-7-1943. Removal of All Axis Nationals from SP Coast. RG 84, v. XXXI.

BLOCKER. 13-10-1942. Removal of Axis Nationals to Interior of ES. RG 84, v. XXXIV.

BRADOCK. 25-9-1942. RG 84, v. XXXIII.

38 FBI. 21-3-1942, op. cit.
} 


\section{A colaboração do Brasil}

Mesmo após a ruptura de relações diplomáticas do Brasil com os países do Eixo, ${ }^{39}$ quando aproximadamente 250.000 japoneses residiam no estado de São Paulo, a maioria dos quais engajados na agricultura e economicamente ativos, uns poucos foram considerados para medidas mais drásticas, como o chamado "internamento em campos". Cioso de sua importância na economia, o governo brasileiro prometeu supervisioná-los. Apesar disso, algumas autoridades estadunidenses acreditavam que havia maior probabilidade de que os japoneses e empresas de propriedade exclusiva de japoneses no Brasil estariam, se pudessem, trabalhando contra os Estados Unidos, mais do que o fariam alemães e italianos não incluídos na Lista. Essa suspeita fazia da nacionalidade japonesa, por princípio, "um bom caso para inclusão", mas o World Trade Intelligence, vinculado ao Departamento de Estado, pedira o cuidado de não encher a Lista com nomes.

A interferência direta e responsabilização do governo Vargas foram bem mais evidentes no caso dos japoneses do que nos de outras nacionalidades inimigas. Por um lado, os japoneses tinham fama, no Brasil, de trabalhadores e de ordeiros, por outro, sua atividade era eminentemente rural e estava vinculada ao atendimento das necessidades de subsistência de grandes centros urbanos. As negociações entre o governo brasileiro e o comitê da PL duraram quase um ano, e ao final se chegaria à remoção de todas as cooperativas japonesas da Lista Negra, não sem antes expurgar ou "nacionalizar" suas diretorias. Em 1942, o governo brasileiro comprometeu-se a eliminar, da administração da Cooperativa de Cotia, os elementos nipônicos. $40 \mathrm{O}$ antigo diretor foi substituído por três brasileiros, e o Ministério da Guerra e o Serviço Econômico Rural do Ministério da Agricultura indicaram representantes para supervisionar as atividades de Cotia. Além das inspeções freqüentes, foi exigida autorização para viagens e censurada a comunicação, foram tomados, pelo governo, dez de seus automóveis, e os motoristas de seus caminhões substituídos por brasileiros. Instituiu-se "uma nova cooperativa central composta inteiramente de brasileiros leais", estabeleceu-se a supervisão de todas as atividades dos membros nipônicos e um controle

39 O corte de relações diplomáticas do Brasil com os países do Eixo deu-se em 28 de janeiro de 1942 e a declaração de guerra em finais de agosto.

40 Despachos 15.226 de 4-4-1944, e 19.207 de 18-12-1944. 
financeiro.41 Em 21 de janeiro de 1943, Cotia foi, por fim, indicada para exclusão da Lista. Outras dezoito cooperativas agrícolas vinham sendo reorganizadas pelo governo e em breve também sairiam da PL. Isso era documentado em números:

Na Cooperativa Agrícola Nippo Bandeirante (ex-PL) existiam, em agosto de 1942, 154 membros dos quais 110 eram japoneses, 27 brasileiros, 12 espanhóis e 5 italianos; em setembro de 1943, dos 202 membros, 114 são japoneses, 80 brasileiros e os demais de outras nacionalidades. A Cooperativa Agrícola Três Barras teve mais sucesso. Existiam apenas 12 membros brasileiros e, em março de 1943, 389.42

Embora tenha havido alguns conflitos violentos entre os próprios membros das comunidades japonesas, motivados, às vezes, pelo corte de informações, em língua japonesa, sobre a posição do Império na guerra, nunca se difundiu no Brasil uma sensação de ameaça real a respeito dos estrangeiros dessa origem. Mesmo a pressão dos Estados Unidos não chegou a ser comparável à exercida em relação aos alemães. Os italianos foram, em geral, bastante poupados em nome de sua integração aos nacionais. Ainda assim também houve ações populares violentas contra os japoneses em agosto de 1942, na onda de ataques a empresas do Eixo. Há relatos de que, em Porto Alegre, os negócios com nomes japoneses visíveis sofreram danos, tiveram janelas e letreiros quebrados. ${ }^{43}$ A Companhia Nipônica de Plantação, que se encontrava na PL, "foi invadida, destruída e fechada permanentemente, seu contrato com o estado do Pará foi cancelado, suas plantações foram tomadas pela polícia estadual para uso como campo de concentração. Quase todos os japoneses no Pará estão agora presos lá. E foi dito oficialmente que, em breve, todos serão presos". ${ }^{44} \mathrm{O}$ cônsul chamou o local de "campo de concentração de Tomé Açu”. A Companhia Industrial Amazonense S. A. (Amazonia Sangyo Kabusshiki Kaisha), empresa formada no Amazonas por japoneses cuja migração fora estimulada pelo governo estadual, ${ }^{45}$ foi bloqueada em 1942, alguns agriculto-

41 Procurement for Strategical Materials, op. cit.

42 TEWELL. 31-1-1945. War Intelligence Files. Records of PL.

43 BRADOCK. List of Property Depredations in Porto Alegre, August 18 and 19, 1942. RG 84, v. XXXIII.

44 McLAUGHLIN. 23-13-1942. Present Condition of Firms Raided by Belem Mobs on August 18, 1942. RG 84, v. XXXIII.

45 http://madeinjapan.uol.com.br/2003/06/08/associacao-conta-a-historia-dosjaponeses-no-amazonas/ Acessado em 6/6/2006. 
res foram presos, houve "reorganização do corpo de diretores", ${ }^{46}$ e seu patrimônio foi leiloado em 1946. Em 1945, continuava a haver alguma coação sobre Vargas para que garantisse o controle sobre os japoneses, e novos trabalhadores brasileiros eram introduzidos nas cooperativas pelos diretores a fim de contrabalançar a participação majoritária nipônica.

Passado o vendaval da guerra, os japoneses permaneceram no Brasil e, embora tenham preservado e difundido seus próprios costumes, integraram-se também aos locais. Muito do que foi construído por eles foi desapropriado na época e não faltaram injustiças. Comparada à repressão que experimentaram em outros países da América, o impacto da guerra sobre os japoneses residentes no Brasil foi bem menos deletério, para o que devem ter contribuído a interferência do governo e o peso que o grupo adquirira na economia. Alguns "indesejáveis" foram substituídos, na administração de cooperativas, por brasileiros "leais", e famílias que residiam em pontos estratégicos e próximos ao litoral foram transferidas para o interior. Decerto essas medidas provocaram sofrimento e incerteza - sempre mais agudos quando se é estrangeiro, "inimigo", e não há perspectivas de retorno ao país de origem. A cultura nipônica, então quase impenetrável para os ocidentais, representou um obstáculo nessas difíceis relações, mas foi a inserção social desses imigrantes que evitou que experimentassem lesões maiores nesse jogo de forças.

46 HART. 14-2-1942. Spot News for the Acre and the State of Amazon during the Week February 6 to February 13, 1942. RG 84, v. XXXIII. 